\title{
Social Class and Mortality
}

\section{Miki Takunaga ${ }^{1}$, Toru Takahashi ${ }^{2}$, RB Singh ${ }^{3 *}$, Fabien De Meester ${ }^{4}$ and DW Wilson ${ }^{5}$}

${ }^{1}$ Department of Nutrition and Health Sciences, Fukuoka Women's University, Fukuoka, Japan

${ }^{2}$ Department of Nutrition, Graduate School of Human Environment Science,Fukuoka Women's University, Japan

${ }^{3}$ Halberg Hospital and Research Institute, Moradabad, India

${ }^{4}$ The Tsim Tsoum Institute, Krakow, Poland

${ }^{5}$ School of Medicine, Pharmacy and Health, Durham University, UK

The United Nation, High Level Meeting (UN-HLM) on deaths and disability due to non-communicable diseases (NCDs), was important to emphasize the Millennium Development Goals for reducing avoidable mortality due to NCDs by $25 \%$ by 2025 (the 25 by 25 goal) [1-3]. The basic societal risk factors resulting in to death and disability and discussion on existing health promotion policies in the developed countries, which are also followed by the developing countries, need further consideration [3-5]. Mortality and burden of disease estimates for WHO, revealed that $36 \cdot 1$ million deaths per year occur as a result of NCDs, which are mainly due to cardiovascular diseases (CVDs) [5]. Approximately, 63\% of premature deaths in adults (aged 15-69 years), and three out of four of all adult deaths are attributable to NCDs. However, some experts during the UN-HLM , proposed that, of total deaths, 22.4 million arise in the poorest countries, and 13.7 million in high-income and upper-middle-income countries and therefore poverty may be the major cause of NCDs (Figure 1) [3,5]. One Indian study shows that $57.0 \%$ of deaths in adults (aged 25-64 years) were due to NCDs,(including $31.0 \%$ due to CVDs), $25.5 \%$ due to communicable diseases, and $15.9 \%$ due to injury and accidents, indicating that our findings on deaths due to NCDs are similar to WHO estimates [6-8]. This study showed that social classes 4,5 had lowest prevalence of deaths and social classes [1-3], having greater income had highest prevalence of deaths due to NCDs (Figure 2). In 1980s, in Kerala State, India, maternal and child mortality rates were lowest and life expectancy and literacy rates were as good as in developed countries in association with rising prevalence of CVDs, but the people were not very wealthy compared to other states of India $[9,10]$.

The epidemic of poor cardiovascular health behavior continue to be common in USA because Americans may have wealth but there is no health compared to 15 other western countries [4,7]. In a recent report of American Heart Association [7] ,after adjustment, population

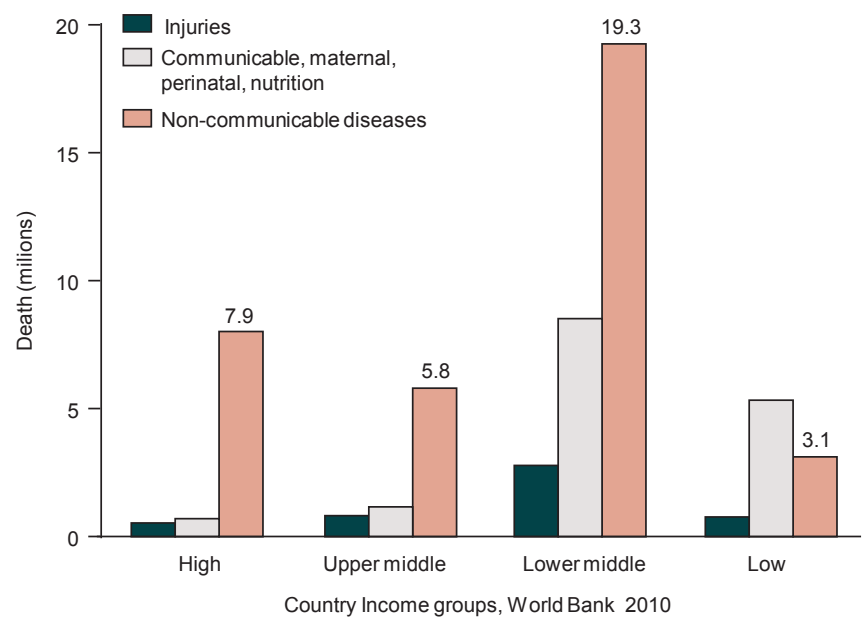

Figure 1:
Social class and mortality due to broad causes of death

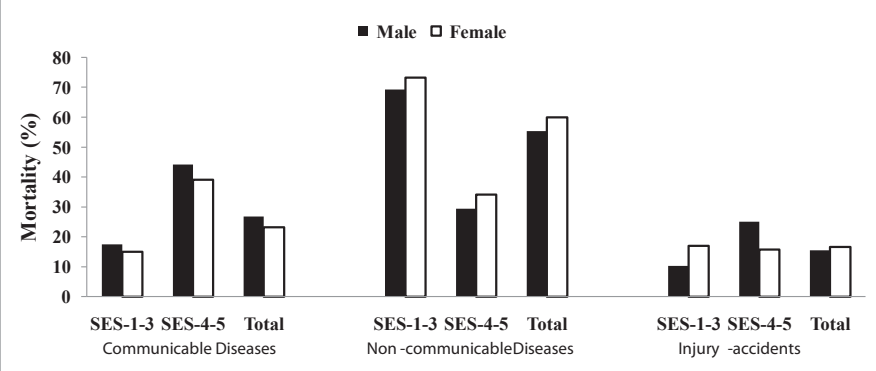

Figure 2: Social classes and mortality due to non-communicable diseases in India.

attributable fractions for CVD mortality were as follows; for high blood pressure, 1: 40.6\% (95\% confidence interval [CI], 24.5-54.6); for smoking 13.7\% (95\% CI, 4.8-22.3); for unhealthy diet 13.2\% (95\% CI, 3.5-29.2); for sedentary behaviour $11.9 \%$ (95\% CI, 1.3-22.3) for high glucose; $8.8 \%$ (95\% CI, 2.1-15.4).

These findings further confirm the old hypothesis that emergence of NCDs may have a sequence during transition from under-nutrition and poverty to affluence; Overweight and central obesity come first in conjunction with deficiency of certain lifestyle related biomarkers having adverse effects on emergence of NCDs. This sequence of development of NCDs may be altered by learning and regular practice of methods of prevention by alteration in public health policies for achieving total health including social, mental and spiritual health, apart from the physical health [10-12].

Acknowledgements are due to International College of Nutrition and the Tsim Tsoum Institute for providing logistic support to write this article.

Conflict of interest has not been declared by any of the authors.

\section{References}

1. Tokunaga M, Takahashi T, Singh RB, Rupini D, Toda E, et al. (2012) Diet Nutrients and Noncommunicable Diseases. The Open Nutraceuticals Journal 5: 146-159

2. Takahashi T, Singh RB, Meester FD, Wilson D (2013) How the 'West' can

${ }^{*}$ Corresponding author: RB Singh, Halberg Hospital and Research Institute, Civil Lines, Moradabad, India, E-mail: rbs@tsimtsoum.net, drkk@dataone.in

Received May 01, 2013; Accepted May 04, 2013; Published May 12, 2013

Citation: Takunaga M, Takahashi T, Singh RB, Meester FD, Wilson DW (2013) Social Class and Mortality. J Socialomics 2: e118. doi:10.4172/21670358.1000e118

Copyright: (C 2013 Takunaga M, et al. This is an open-access article distributed under the terms of the Creative Commons Attribution License, which permits unrestricted use, distribution, and reproduction in any medium, provided the original author and source are credited. 
Citation: Takunaga M, Takahashi T, Singh RB, Meester FD, Wilson DW (2013) Social Class and Mortality. J Socialomics 2: e118. doi:10.4172/2167$0358.1000 \mathrm{e} 118$

overcome unhealthy behaviours to prevent chronic diseases. J Socialomics 2: e114.

3. Beaglehole R, Bonita R, Alleyne G, Horton R, Liming Li, et al. (2011) For the Lancet NCD Group. UN High-Level Meeting on Non-Communicable Diseases: addressing four questions. Lancet 378: 449-55

4. The Lancet (2013) Wealth but not health in USA. Lancet 381: 177.

5. WHO (2010) Mortality and burden of disease estimates for WHO Member States in 2008. Geneva: World Health Organization.

6. Singh RB, Fedacko J, Vargova V, Kumar A, Mohan A, et al. (2011) Singh's verbal autopsy questionnaire for assessment of causes of death, socia autopsy, tobacco autopsy, and dietary autopsy based on medical records and interview. Acta Cardiol 66: 471-481.

7. Sidney S, Rosamond WD, Howard VJ, Luepker RV (2013) The "Hear Disease and Stroke Statistics-(2013) Update" and the Need for a National Cardiovascular Surveillance System. Circulation 127: 21-23.
8. Singh RB, Anjum B, Takahashi T, Martyrosyan DM, Pella D, et al. (2012) Poverty is not the absolute cause of deaths due to non-communi- cable diseases NCDs. World Heart J 4: (in press)

9. Pednekar MS, Gupta R, Gupta PC (2011) Illiteracy, low educational status and cardiovascular mortality in India. BMC Public Health 11: 567.

10. Singh RB, Beegom R, Mehta AS, Niaz MA, De AK, et al. (1999) Social class, coronary risk factors and undernutrition, a double burden of diseases, in women during transition, in five Indian cities. Int J Cardiol 69: 139-147.

11. Moodie R, Stuckler D, Monteiro C, Sheron N, Thamarangsi, et al. (2013) Profits and pandemics: prevention of harmful effects of tobacco, alcohol, and ultraprocessed food and drink industries. The Lancet 381: 670-679.

12. Singh RB, Takahashi T, Nakaoka T, Otsuka K, Toda E, et al. (2013) Nutrition in transition from Homo sapiens to Homo economicus. The Open Nutra J 6 : 6-17. 